\title{
Protective inflammasome activation in AMD
}

\section{Citation}

Chen, Jing, and Lois E H Smith. 2012. Protective Inflammasome Activation in AMD. Nat Med 18, no. 5: 658-660. doi:10.1038/nm.2761.

\section{Published Version}

doi:10.1038/nm.2761

\section{Permanent link}

http://nrs.harvard.edu/urn-3:HUL.InstRepos:33776198

\section{Terms of Use}

This article was downloaded from Harvard University's DASH repository, and is made available under the terms and conditions applicable to Other Posted Material, as set forth at http:// nrs.harvard.edu/urn-3:HUL.InstRepos:dash.current.terms-of-use\#LAA

\section{Share Your Story}

The Harvard community has made this article openly available.

Please share how this access benefits you. Submit a story.

Accessibility 


\title{
Altered Cholesterol Homeostasis in Aged Macrophages Linked to Neovascular Macular Degeneration
}

\author{
Jing Chen ${ }^{1}$ and Lois E.H. Smith ${ }^{1,}{ }^{*}$ \\ ${ }^{1}$ Department of Ophthalmology, Boston Children's Hospital, Harvard Medical School, Boston, MA \\ 02115, USA
}

\section{Abstract}

\begin{abstract}
Abnormal lipid metabolism has been linked to age-related macular degeneration (AMD); choroidal neovascularization in late AMD commonly causes blindness. Sene et al. (2013) now demonstrate that in aged macrophages decreased ABCA1 expression, regulated by liver X receptor and miR-33, impairs export of intracellular cholesterol, which promotes neovascular AMD.
\end{abstract}

\begin{abstract}
Age-related macular degeneration (AMD) is a leading cause of blindness. Subretinal drusen, yellow or white lipid-laden deposits comprising esterified cholesterol and ApoB-containing lipoproteins, are an early hallmark of AMD (Curcio et al., 2010). In dry AMD, drusen formation can progress to geographic atrophy with ultimate degeneration of the light-sensing photoreceptor cells in the macula. However, in $\sim 10 \%$ of patients, AMD progresses to the "wet" form with choroidal neovascularization (CNV), often resulting in rapid and severe central vision loss (Figure 1A). In addition to aging, epidemiologic and genetic studies have identified AMD risk factors in lipid metabolism, including common risk factors for atherosclerosis and immunity/inflammation (Fritsche et al., 2013; Klein et al., 2005). Previous studies have focused on the chemotaxis and drusen-derived activation of inflammatory cells in AMD (Combadière et al., 2007;Doyle et al., 2012). Although lipidrich drusen are associated with macrophages, the link between lipid dysregulation and proangiogenic cell activation in neovascular AMD is not well understood. Macrophages in different tissue environments may exhibit two different phenotypes: M1 and M2. While classic M1 macrophages are proinflammatory and induce TNF- $a$, IL- 6 , and IL- $1 \beta$, the alternatively activated M2 macrophages expressing IL-10 and TGF- $\beta$ are anti-inflammatory and proangiogenic. In this issue, Sene et al. demonstrate that, in aging macrophages, impaired cholesterol efflux due to miR-33-dependent ABCA1 downregulation induces polarization to a proangiogenic M2 form to promote CNV (Sene et al., 2013).
\end{abstract}

Sene et al. show that macrophages isolated from aging mice and humans have reduced levels of the cholesterol transporter ABCA1 and, in mice, higher levels of intracellular cholesterol and oxidized cholesterol metabolites (Sene et al., 2013). In conditional knockout mice, depletion of ABCA1 specifically in macrophages results in increased cholesterol retention in macrophages and, importantly, significantly increases neovascularization in laser-induced $\mathrm{CNV}$, an animal model for neovascular AMD. Interestingly, increased dietary intake of cholesterol with a high-fat diet in mice is also associated with the same phenotypic "aging" changes in macrophages and also with increased laser-induced CNV. The authors then demonstrate that cholesterol content in macrophages regulates CNV by promoting

C)2013 Elsevier Inc.

"Correspondence: lois.smith@ childrens.harvard.edu. 
macrophage polarization into a proangiogenic M2 phenotype. They show that ABCA1 levels may be mediated by both liver X receptor (LXR) and miR-33. Importantly, either activation of LXR with a synthetic agonist or inhibition of miR-33 with LNA miR-33 inhibitor can protect against laser-induced CNV (Figure 1B).

While this study establishes the importance of macrophage cholesterol content in inducing $\mathrm{CNV}$, an issue that remains to be addressed is how intracellular cholesterol dictates their polarization and activation state from an M1 to an M2 phenotype to induce angiogenesis. Recent studies in AMD show an important role for inflammasomes, intracellular protein complexes activated by extracellular or endocytosized particles (Doyle et al., 2012; Tarallo et al., 2012). Perhaps activation of inflammasomes by intracellular cholesterol may contribute to macrophage polarization. Another question emerging from the present study is how aging macrophages acquire the senescent phenotype, since the average macrophage life span is less than 20 days. Do they inherit senescence information from the progenitor cells, or are newly formed macrophages rapidly turned into a senescent phenotype in response to an aged retinal environment with increased oxidative stress? The authors suggest that in aging macrophages, ABCA1 expression may be mediated by increased levels of miR-33. miR-33 is a microRNA embedded within the gene encoding sterol-regulatory elementbinding factor-2 (SREBF-2), a transcriptional regulator of cholesterol synthesis. Recently, miR-33 was found to regulate cholesterol efflux through ABCA1 and ABCG1 and highdensity lipoprotein (HDL) biogenesis (Rayner et al., 2010). It is interesting that Dicer1, a miRNA processing enzyme, is also implicated in inducing Alu RNA toxicity in retinal pigment epithelial cells (RPE) in AMD (Tarallo et al., 2012). This may suggest that defective RNA processing in aging cells, possibly in both RPE and macrophages, may contribute to senescence.

Together, the findings from this paper suggest cholesterol metabolism, and specifically ABCA1 and its regulators LXR and miR-33, as new therapeutic targets for treating neovascular AMD. Current treatment of wet AMD focuses on anti-VEGF therapy, which successfully suppresses CNV. However, therapies that prevent CNV would be desirable. The idea of targeting cholesterol transporter ABCA1 is consistent with ABCA1 being genetically linked to AMD risk (Chen et al., 2010). ABCA1 expression can be directly enhanced by LXR, a transcription factor and also a nuclear receptor for oxidized cholesterol. However, many other genes involved in lipid metabolism such as apolipoprotein E and lipoprotein lipase are also direct transcriptional targets of LXR. Whether the effect of LXR activation is mediated exclusively through ABCA1 may be elucidated using an LXR agonist in ABCA1-deficient mice. Alternatively, inhibition of miR-33 may offer a novel and appealing approach to treat neovascular AMD, considering that inhibition of miR-33 was recently found to promote regression of atherosclerosis and normalization of dyslipidemias in animal models. It is interesting that statins inhibiting HMG-CoA reductase and cholesterol synthesis are widely used to lower serum cholesterol to reduce cardiovascular disease risk. Though AMD and atherosclerosis share common risk factors, clinical studies have failed to conclusively link statin use with reduced AMD risk (Peponis et al., 2010). This new study suggests that modulating intracellular cholesterol levels in macrophages via targeting ABCA1, LXR, and miR-33 may be more important than lowering systemic serum levels in AMD.

While this paper shows convincing data on macrophage cholesterol homeostasis in CNV formation in wet AMD, the implication of these findings in dry AMD, the more common form without $\mathrm{CNV}$, is less clear. It is unknown if influencing macrophage activation may help prevent drusen accumulation and photoreceptor degeneration. Do the cholesterol-laden macrophages contribute to drusen formation when they die, or are they simply unable to phagocytose lipid components to prevent cholesterol/lipid buildup in drusen? Is ABCA1- 
dependent cholesterol transport in photoreceptors and RPE as important for CNV and drusen formation? Answering these questions will require further research.

Collectively, Sene et al. clearly demonstrate that cholesterol homeostasis via ABCA1 in aging macrophages is important for CNV. Proving this is true in humans in neovascular AMD requires further investigation, as the inflammatory response in mice and human may be very different. However, this new study brings us closer to understanding important cellular lipid metabolism regulation in macrophages underlying the pathogenesis of $\mathrm{CNV}$ and suggests therapeutic potential in targeting cholesterol trafficking in inflammatory cells in AMD.

\section{REFERENCES}

Chen W, Stambolian D, Edwards AO, Branham KE, Othman M, Jakobsdottir J, Tosakulwong N, Pericak-Vance MA, Campochiaro PA, Klein ML, et al. Complications of Age-Related Macular Degeneration Prevention Trial Research Group. Proc. Natl. Acad. Sci. USA. 2010; 107:7401-7406. [PubMed: 20385819]

Combadière C, Feumi C, Raoul W, Keller N, Rodéro M, Pézard A, Lavalette S, Houssier M, Jonet L, Picard E, et al. J. Clin. Invest. 2007; 117:2920-2928. [PubMed: 17909628]

Curcio CA, Johnson M, Huang JD, Rudolf M. J. Lipid Res. 2010; 51:451-467. [PubMed: 19797256]

Doyle SL, Campbell M, Ozaki E, Salomon RG, Mori A, Kenna PF, Farrar GJ, Kiang AS, Humphries MM, Lavelle EC, et al. Nat. Med. 2012; 18:791-798. [PubMed: 22484808]

Fritsche LG, Chen W, Schu M, Yaspan BL, Yu Y, Thorleifsson G, Zack DJ, Arakawa S, Cipriani V, Ripke S, et al. The AMD Gene Consortium. Nat. Genet. 2013 in press. Published online March 3, 2013. http://dx.doi.org/10.1038/ng.2578.

Klein RJ, Zeiss C, Chew EY, Tsai JY, Sackler RS, Haynes C, Henning AK, SanGiovanni JP, Mane SM, Mayne ST, et al. Science. 2005; 308:385-389. [PubMed: 15761122]

Peponis V, Chalkiadakis SE, Bonovas S, Sitaras NM. Clin Ophthalmol. 2010; 4:865-869. [PubMed: 20714364]

Rayner KJ, Suárez Y, Dávalos A, Parathath S, Fitzgerald ML, Tamehiro N, Fisher EA, Moore KJ, Fernández-Hernando C. Science. 2010; 328:1570-1573. [PubMed: 20466885]

Sene A, Khan AA, Cox D, Nakamura REI, Santeford A, Kim BM, Sidhu R, Onken MD, Harbour JW, Haqbi-Levi S, et al. Cell Metab. 2013; 17:549-561. this issue. [PubMed: 23562078]

Tarallo V, Hirano Y, Gelfand BD, Dridi S, Kerur N, Kim Y, Cho WG, Kaneko H, Fowler BJ, Bogdanovich S, et al. Cell. 2012; 149:847-859. [PubMed: 22541070] 
Age-related macular degeneration

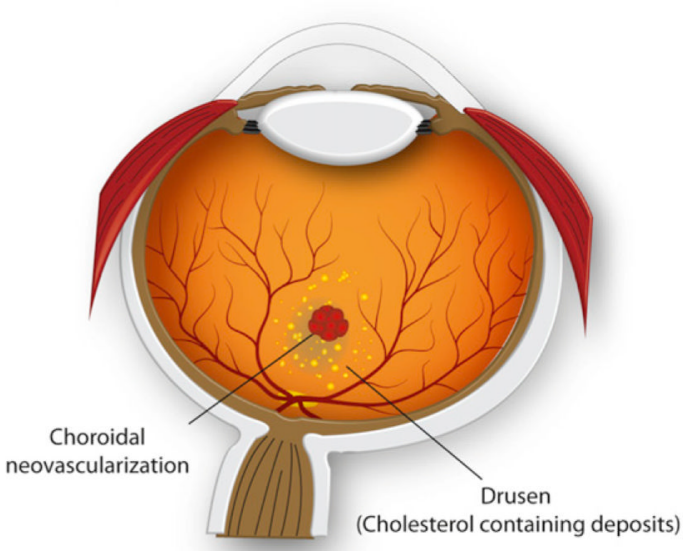

B

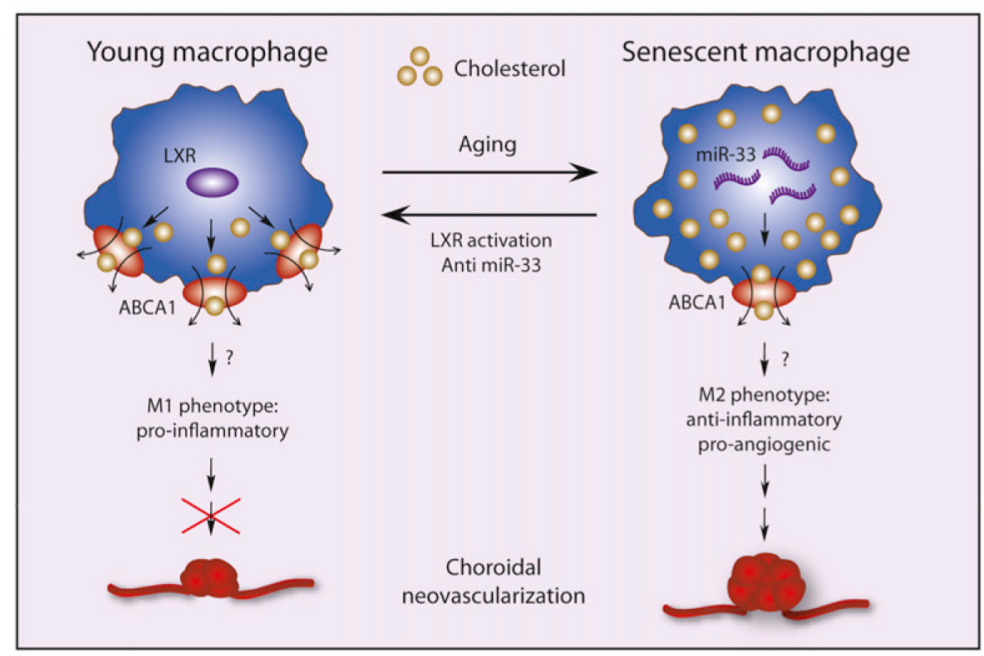

Figure 1. ABCA1-Mediated Cholesterol Efflux Influences Choroidal Neovascularization (A) A schematic drawing of a human eye illustrates cholesterol containing drusen (yellow spots) and choroidal neovascularization (CNV) in the macula. (B) Aging induces increased levels of miR-33, leading to decreased expression of cholesterol transporter ABCA1. Lack of ABCA1 results in impaired cholesterol efflux from macrophages, leading to alternative activation of macrophages from the classic M1 phenotype to the proangiogenic M2 phenotype, and thereby promotes laser-induced CNV formation. Activation of liver X receptor (LXR), a nuclear transcription factor, and inhibition of miR-33 both lead to increased $\mathrm{ABCA} 1$ and protection against $\mathrm{CNV}$. 